\title{
Interactive Instructional Device
}

\author{
Paul Juinn Bing Tan ${ }^{1,2}$, Ming-Hung $\mathrm{Hsu}^{3,4}$ \\ 1. Department of Applied Foreign LanguageNational Penghu University of Science and Technology \\ No.300, Liuhe Rd., Magong City, Penghu County, Taiwan \\ 3. Department of Electrical Engineering National Penghu University of Science and Technology \\ No.300, Liuhe Rd., Magong City, Penghu County, Taiwan \\ 2.pashatan@yahoo.com.tw; tanjuinnbing@gmail.com \\ 4.hsu@gms.npu.edu.tw
}

\begin{abstract}
This interactive instructional device comprises an arithmetic processing unit, input unit, storage unit, and display unit. The arithmetic processing unit contains a logging module and instructional program. The instructional program features multiple instructional sections containing instructions that are viewed through the display unit. Each section corresponds with a passing criteria. When the passing criteria is fulfilled, corresponding instructions are displayed through the display unit. Thus, interactive instruction can be achieved using this device.[1]
\end{abstract}

Key words: Interactive Instruction, Culture Learning, System Design, E-course

\section{Introduction}

This computer system is an interactive instructional device. Ongoing developments in computer technology have made computers a necessity in every household. Typically, story-based computer games are not developed specifically for educational purposes; instead, they are generally developed for profit. [2,12-15]

However, previous studies have maintained that games are considerably meaningful to children, and they are the most natural approach for them to express their emotions. Jerome Seymour Bruner, a psychologist and educationalist from the United States, indicated that relying only on teacher knowledge is an incomprehensive approach to educating children. [3-11, 12-16]

\section{Design of Model Content}

This interactive instructional device is designed to achieve the objective of improving children's learning effectiveness by assisting them to learn through educational computer games. $[2-10,11-16]$ To achieve this objective, the interactive instructional device includes an arithmetic processing unit, input unit, storage unit, and display unit:

The arithmetic processing unit comprises a logging module containing an account name and password and an instructional program containing multiple instructional sections and an interface for level selection. Each section contains instructions corresponding to a specific passing criteria. When a condition is fulfilled, the corresponding instructions are displayed on the display unit.

The input unit is electrically connected to the arithmetic processing unit and enables users to input their account name and password and execute various system commends.

The storage unit is electrically connected to the arithmetic processing unit and saves user operation record.

The display unit is electrically connected to the arithmetic processing unit and enables the user to view the content and description screens of the instructional program to be displayed.

Ideally, the level selection interface enables users to set the game difficulty to easy, hard, or advanced level. Three-dimensional graphics can be rendered through the display unit when the instructional program is executed using the arithmetic processing unit. The input unit can be a keyboard, mouse, or both.

The aforementioned objective and advantages of this product are further explained in the following descriptions and figures. (figure 1-3)

\section{The Method of System Installation}

\section{【Figure Explanation】}

Figure 1 is a block diagram of the system of this product.

Figure 2 is a schematic diagram of the product's usage state for the login authentication screen of the logging module.

Figure 3 is a schematic diagram of the product's usage state for the selection screen of the level selection interface.

【Implementation Approach】

Please refer to Figures 1-3. The interactive instructional device consists of arithmetic processing unit (11), input unit (21), storage unit (31), and display unit (41). Users can enter system commands through the input unit (21) to control the arithmetic processing unit (11), which executes the instructional program, to display the program on the display unit (41), or to save user operation records in the storage unit (31), detailed as follows:

The arithmetic processing unit (11) is a computer comprising a logging module (12) and instructional program (13). The 
logging module (12) contains an account name and password. Through the execution of the arithmetic processing unit (11), the logging module (12) displays the login authentication screen (121) via the display unit (41). Users must enter their account name and password correctly, which are verified by the logging module (12), to execute the instructional program (13). The instructional program (13) is a story-based computer game (e.g., Journey to the West, Romance of the Three Kingdoms, and Water Margin). Moreover, the instructional program (13) contains a level selection interface (131) and multiple instructional sections. The level selection interface (131) is displayed in the display unit (41) after the user account information has been authenticated by the logging module (12). The level selection interface (131) enables users to set the difficulty of the game to easy, hard, or advanced. Each instructional section corresponds with instructional content that is shown in the display unit (41) using three-dimensional graphics through the execution of instructional program (13) by the arithmetic processing unit (11). Additionally, each section includes a passing criteria; after a condition has been fulfilled, the description screen of the instructional section corresponding to the condition is displayed on the display unit (41). The passing criteria range from defeating specific game characters to collecting specific quest items. The description screens are brief story-based scenarios corresponding to their respective instructional sections. Thus, interactive instruction is achieved.

The input unit (21) can be a keyboard, mouse, or both. Input Unit (21) is electrically connected to the arithmetic processing unit (11) to enable users to input their account name and password, and to execute various system commands.

The storage unit (31) is electrically connected to the arithmetic processing unit (11) for saving user operation records and data. The display unit (41) is a display screen that is electrically connected to the arithmetic processing unit (11), through which the description screens of the instructional content of the instructional program (13) can be viewed.

\section{Conclusion}

This product enables users to learn about Chinese culture through playing story-based computer games (e.g., Journey to the West, Romance of the Three Kingdoms, and Water Margin).

The instructional program in this product is a single-player game that does not require an Internet connection to play. Users are only required to register their accounts directly on the platform of the supplier. The platform then transmits a verification message to the user's mobile phone to setup the user's account name and password for the logging module.

Examples of social networking sites include Face book, My Space, and LinkedIn. The purpose of such sites is to enable participants to share thoughts, activities, photos, videos, and links to websites with the members of their social network. Through the network, users can share events and ideas with numerous other participants simultaneously. An entire class can enjoy this type of activity, and students do not have to be highly proficient in a language to participate. Whenever possible, authentic language should be introduced. Students play a language game. Games can serve as effective teaching tools due to their sharing of certain features with actual communicative events; in other words the language exchange has a purpose. In addition, players receive immediate feedback from the other players regarding whether they communicated successfully.

Technology has long been associated with language teaching. For many years, the technology used in teaching languages essentially consisted of only chalk and blackboards. More recently, however, various other technologies and media, including films, videos, audio files, and playback equipment have become available for teachers to use. In addition, digital technological resources can be used by teachers. The Internet, which connects millions of computers around the world, enables individual computers to communicate with each other. Furthermore, computers provide the means to access online dictionaries, grammar and style resources, and concordances. Computers even determine how we view the nature of that what is taught.

\section{【Description of the Symbols】}

Arithmetic processing unit (11)

Logging module (12)

Login authentication screen (121)

Instructional program (13)

Level selection interface (131)

Input unit (21)

Storage unit (31)

Display unit (41)

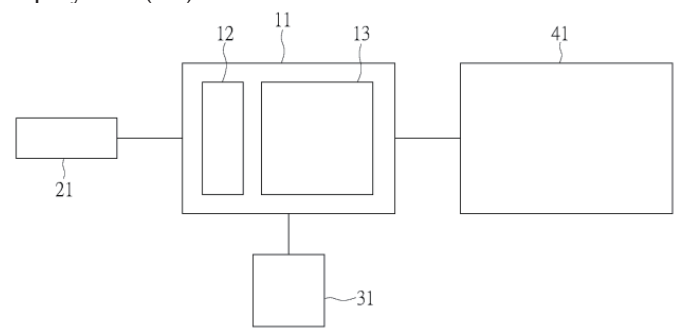

Figure 1 is a block diagram of the system of this product.

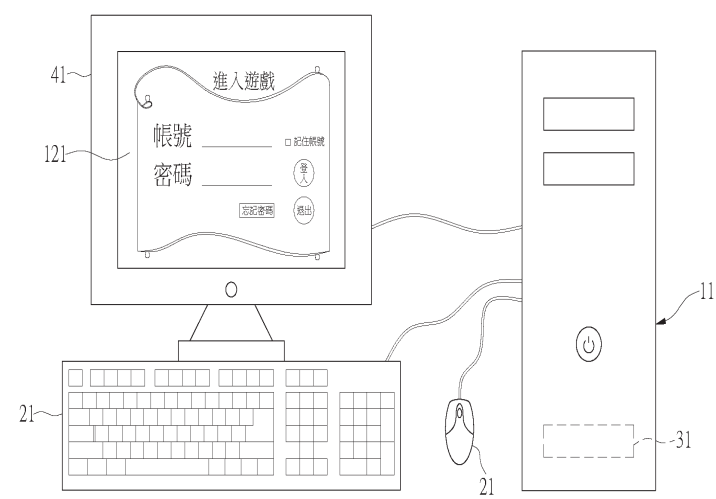

Figure 2 is a schematic diagram of the product's usage state for the login authentication screen of the logging module. 


\section{Recent Developments on Information and Communication Technology (ICT) Engineering- Meen, Yang \& Zhao \\ ISBN: 978-981-14-2136-5}

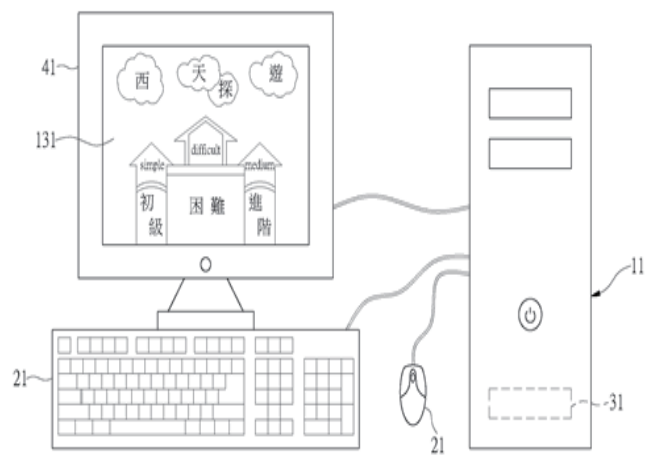

Figure 3 is a schematic diagram of the product's usage state for the selection screen of the level selection interface.
Language): Taiwanese citizens' acceptance and use of the Modular Object-Oriented Dynamic Learning

Environment," Social Science Information, p. 211-228, 2015.

15. Paul Juinn Bing Tan \& Ming-Hung Hsu, Patent of Taiwan (2015) Interactive Instructional Device patent NO: M488712

16. Paul Juinn Bing Tan \& Ming-Hung Hsu (2018) Designing a System for English Evaluation and Teaching Devices: A PZB and TAM Model Analysis. EURASIA Journal of Mathematics, Science and Technology Education 14(6):2107-2119

\section{References}

1. Ariel, Y., \& Avidar, R. (2015). Information, interactivity, and social media. Atlantic Journal of Communication, 23(1), 19- 30.

2. Avidar, R. (2013). The responsiveness pyramid: Embedding responsiveness and interactivity into public relations theory. Public Relations Review, 39, 440-450.

3 Bruner, J. (1960). The Process of Education. Cambridge, MA: Harvard University Press.

4. Bruner, J. (1966). Toward a Theory of Instruction. Cambridge, MA: Harvard University Press.

5. Bruner, J. (1973). Going Beyond the Information Given. New York: Norton.

6. Bruner, J. (1983). Child's Talk: Learning to Use Language. New York: Norton.

7. Bruner, J. (1986). Actual Minds, Possible Worlds. Cambridge, MA: Harvard University Press.

8. Bruner, J. (1990). Acts of Meaning. Cambridge, MA Harvard University Press.

9. Bruner, J. (1996). The Culture of Education, Cambridge, MA: Harvard University Press.

10. Bruner, J. Goodnow, J., \& Austin, A. (1956). A Study of Thinking. New York: Wiley.

11. Bruner, J. (2003). The Culture of Education. Harvard Univ. Press

12. P. J. B. Tan, "Applying the UTAUT to understand factors affecting the use of English e-learning websites in Taiwan," Sage Open, vol. 3, p. 1-12, 2013.

13. P. J. B. Tan, "Students' adoptions and attitudes towards electronic placement tests: A UTAUT analysis," American Journal of Computer Technology and Application, vol. 1, pp. 14-23, 2013.

14. P. J. B. Tan, "English e-learning in the virtual classroom and the factors that influence ESL (English as a Second 
Recent Developments on Information and

Communication Technology (ICT) Engineering- Meen, Yang \& Zhao ISBN: 978-981-14-2136-5 